\title{
Covalently-linked insulin dimers: their metabolism and biological effects in vivo as partial competitive antagonists of insulin clearance
}

\author{
M. A. Tatnell, R.H. Jones and P. H. Sönksen \\ Department of Medicine, St. Thomas' Hospital Medical School, London, UK
}

\begin{abstract}
Summary. The biological properties of three covalently-linked insulin dimers were studied in greyhounds. Constant infusions showed that the plasma distribution kinetics were slower for the dimers than for insulin. The metabolic clearance rates of the three dimers $\left(10.3 \pm 0.4,8.8 \pm 0.5,8.2 \pm 0.5 \mathrm{ml} \cdot \mathrm{min}^{-1}\right.$. $\mathrm{kg}^{-1}$; mean $\left.\pm \mathrm{SEM}\right)$ were significantly lower than that of insulin $\left(19 \pm 0.8 \mathrm{ml} \cdot \mathrm{min}^{-1} \cdot \mathrm{kg}^{-1}\right)$, and their hypoglycaemic effects $(11.2 \%, 3 \%$ and $0.3 \%)$ were markedly reduced compared with their lipogenic potencies in vitro $(80 \%, 30 \%$ and $13 \%$, respectively). A low dose infusion of insulin or an equipotent dose of one of the dimers significantly prolonged the effects of an insulin bolus on plasma glucose but not on non-esterified fatty acids. The apparent distribution space $(106.4 \pm 11.9 \mathrm{ml} / \mathrm{kg})$
\end{abstract}

and clearance rate $\left(14.7 \pm 0.5 \mathrm{ml} \cdot \mathrm{min}^{-1} \cdot \mathrm{kg}^{-1}\right)$ of an insulin bolus were significantly reduced by one dimer $(44.5 \pm 8.4 \mathrm{ml} /$ $\mathrm{kg}$ and $10.7 \pm 2.8 \mathrm{ml} \cdot \mathrm{min}^{-1} \cdot \mathrm{kg}^{-1}$ ) but not by the equipotent insulin infusion $(102.7 \pm 8.2 \mathrm{ml} / \mathrm{kg}$ and $16.4 \pm 0.07 \mathrm{ml}$. $\left.\min ^{-1} \cdot \mathrm{kg}^{-1}\right)$. The apparent partial competitive antagonism of insulin by the dimers that has been reported in vitro can be observed in vivo, in that antagonism of insulin metabolism was directly demonstrated with one of the dimers.

Key words: Chemically-modified insulins, insulin structurefunction, bioactivity and metabolism in vivo, competitive antagonism, hypoglycaemia, non-esterified fatty acids.
For chemically-modified monomeric insulins close correlations have been reported between biological properties in vivo and receptor binding affinities or biochemical responses in vitro [1]. Moreover, insulin derivatives with modifications in or near the putative receptor binding region $(\mathrm{A} 1,5,19,21$ and $\mathrm{B} 12,16,22-26)[2,3]$ exhibited parallel reductions in their rates of metabolism and hypoglycaemic potencies, whereas those insulins modified at other residues, such as at B1 or B29, retained full or nearly full metabolism and biological expressions [4]. These studies suggest highly specific structural requirements for insulin metabolism and action.

We have previously reported that covalently-linked insulin dimers possessed unusual properties in vitro. In particular, their binding affinities for insulin receptors in various tissues were markedly higher than their lipogenic or anti-lipolytic potencies in isolated rat adipocytes $[5,6]$. We have now studied three dimers in greyhounds to determine the physiological implications of these unusual features. Since the observations in vitro suggested that the dimers behaved as partial antagonists of insulin, this aspect was also investigated directly in vivo with one of the dimers.

\section{Materials and methods}

Three covalently-linked insulin dimers were prepared and kindly donated by Drs. A.Schüttler and D. Brandenburg, Deutsches Wollforschungsinstitut, Aachen, FRG [7] $\left(\mathrm{N}^{\mathrm{B} 1}, \mathrm{~N}^{\mathrm{B} 29}\right.$-suberoyl-insulin dimer (B1-B'29 D), $\mathrm{N}^{\mathrm{B} 1}, \mathrm{~B}^{\mathrm{B} 1}$-suberoyl-insulin dimer (B1-B'1 D), and $\mathrm{N}^{\mathrm{B} 29}$, $\mathrm{N}^{\mathrm{B} 29}$-suberoyl-insulin dimer (B29-B'29 D)). Highly purified bovine insulin was supplied by the same group, and porcine insulin by Novo, Copenhagen. For intravenous administration, materials were in isotonic saline $(0.154 \mathrm{~mol} / 1)$ containing $0.5 \%$ human serum albumin.

\section{Experimental protocols}

Mature greyhounds of both sexes (weight $26.7-36 \mathrm{~kg}$ ) were anaesthetised intravenously with sodium pentobarbitone $(30 \mathrm{~g} / \mathrm{kg}$ body weight) after an overnight fast. Body temperature was maintained by a warming pad and the dogs were artificially ventilated to a constant end-tidal $\mathrm{CO}_{2}$ concentration of $4-5 \%$, as measured by an infra-red capnograph (Godart, Bilthoven, The Netherlands). After 30 min for baseline sampling, dimer was infused into a saphenous vein at a single constant rate for $3.5 \mathrm{~h}$ at either $1.0-1.5 \mathrm{pmol} \cdot \mathrm{min}^{-1} \cdot \mathrm{kg}^{-1}$ (low dose) or $2.8-6.2 \mathrm{pmol} \cdot \mathrm{min}^{-1} \cdot \mathrm{kg}^{-1}$ (high dose). Sampling from a jugular vein continued for $60 \mathrm{~min}$ after termination of the infusion. Two or three experiments were performed at each dose with each dimer. On the assumption that each half of a dimer could be a potentially active insulin molecule, at each dose level bovine insulin was infused at approximately twice the molar rate of the dimers. During insulin infusion, dangerous hypoglycaemia was prevented by limiting the time of 
the low-dose infusion $\left(2.7-3.6 \mathrm{pmol} \cdot \mathrm{min}^{-1} \cdot \mathrm{kg}^{-1}\right)$ to $2 \mathrm{~h}$, and by using a simple glucose clamp to maintain plasma glucose concentrations at $3 \mathrm{mmol} / \mathrm{I}$ with the high-dose infusion $\left(8.2-14.1 \mathrm{pmol} \cdot \mathrm{min}^{-1} \cdot \mathrm{kg}^{-1}\right)$.

In a second set of experiments with non-anaesthetised greyhounds (after an overnight fast), either saline $(0.154 \mathrm{~mol} / 1)$ or equipotent doses of insulin or B1-B'29 D were infused in the presence of a bolus of insulin to detect interaction between insulin and the dimer. The dose of insulin that was empirically found to be equipotent with B1-B'29 D at $4.90 \pm 0.46 \mathrm{pmol} \cdot \mathrm{min}^{-1} \cdot \mathrm{kg}^{-1}$ was $1.40 \pm 0.08 \mathrm{pmol} \cdot$ $\mathrm{min}^{-1} \cdot \mathrm{kg}^{-1}$ (Fig. 1). The dogs showed no outward signs of stress during the experiments, which consisted of a priming dose of $335 \pm$ 19 pmol insulin or $1302 \pm 153$ pmol B1-B'29 D followed by a 90 -min constant infusion (into a cephalic vein) of insulin, dimer, or saline. A bolus injection of porcine insulin 173 or $700 \mathrm{pmol} / \mathrm{kg}$ body weight was administered $30 \mathrm{~min}$ into the infusion. Sampling at 5 -min intervals from a saphenous vein began immediately before the infusion and continued for $15 \mathrm{~min}$ after termination, with an additional sample 2 min after the bolus injection.

\section{Assay methods}

Plasma glucose concentration was measured by a glucose oxidase method (Yellow Springs Instruments glucose analyser, Yellow Springs, Ohio, USA); plasma non-esterified fatty acids (NEFA) were determined by the method of Dole and Meinertz [8]; and immunoreactive insulin or dimer levels were measured by a modification [9] of a double-antibody radioimmunoassay [10] (using charcoal-treated dog serum in place of human serum). An anti-insulin serum was selected that cross-reacted equally well with equal masses of insulin and of the dimers. Samples from the interaction experiments that contained a mixture of insulin and B1-B'29 D showed the same cross-reactivity with the antiserum as did equal masses of the individual materials. Bovine insulin was radiolabelled as previously described [11].

\section{Calculations}

The initial half-disappearance time of all materials studied $\left(t_{y_{2}}\right)$ was derived graphically from a semi-logarithmic plot of the serum disappearance curve after termination of the infusion. Metabolic clearance rate (MCR) and apparent distribution space (DS) were determined from the constant-infusion data.

$$
\begin{aligned}
& \operatorname{MCR}\left(\mathrm{ml} \cdot \min ^{-1} \cdot \mathrm{kg}^{-1}\right)=\frac{\text { infusion rate }\left(\mathrm{pmol} \cdot \mathrm{min}^{-1} \cdot \mathrm{kg}^{-1}\right)}{\text { steady-state analogue level }(\mathrm{pmol} / \mathrm{ml})} \\
& \operatorname{DS}(\mathrm{ml} / \mathrm{kg})=\frac{\operatorname{MCR}\left(\mathrm{ml} \cdot \mathrm{min}^{-1} \cdot \mathrm{kg}^{-1}\right) \times \mathrm{t}_{1 / 2}(\mathrm{~min})}{0.693}
\end{aligned}
$$

Metabolic clearance rates and apparent distribution spaces were determined from the bolus data after subtraction of background infusion values and analysis of the disappearance curves by a double exponential curve-fitting program written by Dr. M.D. Baron for use on a Z-80A-based microcomputer.

$\operatorname{MCR}\left(\mathrm{ml} \cdot \mathrm{min}^{-1} \cdot \mathrm{kg}^{-1}\right)$

$$
=\frac{\text { dose }(\mathrm{pmol})}{\text { area under curve }\left(\mathrm{pmol} \cdot \mathrm{ml}^{-1} \cdot \min \right) \times \operatorname{dog} \text { weight }(\mathrm{kg})}
$$

$\mathrm{DS}\left(\mathrm{ml} \cdot \mathrm{kg}^{-1}\right)$

$$
=\frac{\text { dose }(\mathrm{pmol})}{\text { sum of } 2 \mathrm{y} \text {-intercepts }(\mathrm{pmol} / \mathrm{ml}) \times \operatorname{dog} \text { weight }(\mathrm{kg})}
$$

Biopotencies in vivo of chemically-modified insulins have been reported significantly higher when hypoglycaemic activity has been related to the total dose of material administered than when calculated in relation to the serum steady-state level actually achieved. The latter method allows for differences in the rates at which the materials are metabolised, and correlates well with potencies in vitro when monomeric insulin analogues are studied. Unless stated otherwise, dimer biopotency in vivo has been calculated by relating hypoglycaemic response to serum steady-state level achieved [1]. An experimental protocol of primed 30-min infusion periods was originally used to determine dimer potencies. However in view of the slow kinetics of the

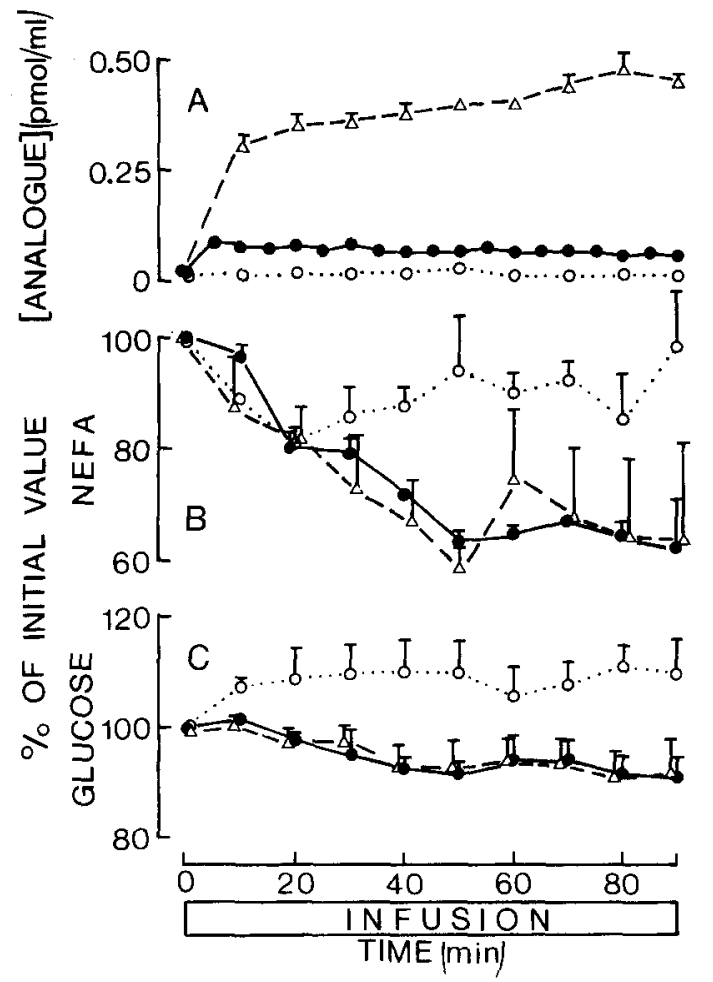

Fig. 1 A-C. Infusions of saline $(0.154 \mathrm{~mol} / \mathrm{l})(\mathrm{O} \ldots \mathrm{O})$ or equipotent doses of insulin $\left(-, 1.40 \pm 0.08 \mathrm{pmol} \cdot \mathrm{min}^{-1} \cdot \mathrm{kg}^{-1}\right)$ or B1-B'29 D $\left(\Delta-\triangle, 4.90 \pm 0.46 \mathrm{pmol} \cdot \mathrm{min}^{-1} \cdot \mathrm{kg}^{-1}\right)$. Data from three experiments with each substance are means \pm SEM (when error bars are not shown variance is smaller than symbol) for A plasma immunoreactive analogue levels, Bnon-esterified fatty acids (NEFA) and Cglucose

dimers it is possible that even with the priming doses true serum steady-state levels had not been achieved, leading to errors in the estimates. Further estimates of potencies from the experiments reported here have been undertaken as follows. On the assumption that the dose-response relationship between steady-state levels of hormone and fall in plasma glucose from baseline (SSL versus $\Delta \mathrm{G}$ ) was parallel between insulin and each of the dimers, data from the interaction experiments could be regarded as a single point bioassay for B1-B'29 D. Its biopotency was determined from the steady-state levels of the equipotent doses of insulin and B1-B'29 D, using only the last few data points of the 90-min infusion of B1-B'29 D when a true steady state level had been achieved (Fig. 1).

Potency $\left(\%\right.$ B1-B'29 D) $=\frac{\text { SSL (insulin) }}{\text { SSL (B1-B'29 D) }} \times 100 \%$

Using this calculated potency for B1-B'29 D, the biopotency of each of the other two dimers was estimated from the two doses of the $3.5-\mathrm{h}$ infusions by relating their steady state levels and the falls in plasma glucose concentration after $120 \mathrm{~min}$ of infusion to the respective values for B1-B'29 D. Potency of dimer

$$
=\frac{\Delta \mathrm{G} \text { (dimer) }}{\Delta \mathrm{G}\left(\mathrm{B} 1-\mathrm{B}^{\prime} 29 \mathrm{D}\right)} \times \frac{\mathrm{SSL}\left(\mathrm{B} 1-\mathrm{B}^{\prime} 29 \mathrm{D}\right)}{\mathrm{SSL} \text { (dimer) }} \times \% \mathrm{~B}^{\prime}-\mathrm{B}^{\prime} 29 \mathrm{D}
$$

\section{Statistical analyses}

For each metabolic variable calculated from either infusion or bolus data, a one-way analysis of variance was used to determine the significance of difference $(p<0.05)$, either between insulin and the dimers, or between control, insulin and B1-B'29 D in the interaction experiments. A two-way analysis of variance was used to compare the effects of insulin and dimer on plasma glucose and NEFA in the interaction experiments. 


\section{Results}

Constant infusions of insulin and the three dimers, given separately, showed that the plasma distribution kinetics of the dimers were slower than those of insulin. Whereas insulin achieved a steady-state level by $20 \mathrm{~min}$ into the infusion, the dimers did not reach a steady state until 60-110 min during the low-dose (a representative infusion of each is shown in Fig. 2) and 100-150 min during the high-dose infusions. The mean steady-state levels achieved at each dose are shown in Figure 3A. All three dimers showed significantly reduced rates of metabolism ( $p<0.001$, Fig. 3B), which was also reflected in their prolonged half-time of disappearance from serum $(p<0.001$, Fig. 3C). During the low-dose infusions the hypoglycaemic effects were markedly reduced for the dimers compared with insulin $(p<0.001$, Fig.3D). At both dose levels of dimers, B1-B'29 D was the most and B29-B'29 D the least active. This relative order of the dimers for biological potencies was also observed in vitro [5, 7]. The apparent distribution space of the dimers $(77.1 \pm 7.6$ to $94 \pm 13.7 \mathrm{ml} / \mathrm{kg})$ did not significantly differ from that of insulin $(90.4 \pm 7.5 \mathrm{ml} / \mathrm{kg})$.

Our findings in vitro that the binding potencies of the dimers were 2.5 to 6.6 -fold higher than their biological potencies suggested that covalent insulin dimers were partial competitive antagonists of insulin. The most active dimer, B1-B'29 D, was selected to investigate the possibility of an interaction with insulin. Figure 4 illustrates the results of these experiments, in which an insulin bolus ( $700 \mathrm{pmol} / \mathrm{kg}$ ) was given $30 \mathrm{~min}$ into a 90 -min infusion of either saline or equipotent doses of insulin or dimer (1.4 and $4.9 \mathrm{pmol} \cdot \mathrm{min}^{-1} \cdot \mathrm{kg}^{-1}$ respectively). The mean plasma immunoreactive analogue concentrations are shown in Figure 4, panel A. Both infusions significantly reduced plasma NEFA before the insulin bolus was given $(p<0.05)$, but did not alter the recovery of NEFA $30 \mathrm{~min}$ after the bolus (Fig.4, panel B). Both infusions had little effect on plasma glucose levels before the insulin bolus (NS), but markedly prolonged the hypoglycaemic effect of the bolus until the end of the infusion $(p<0.001$, Fig. 4 , panel C). This prolongation of hypoglycaemia was found to be dose-dependent, as an infusion of insulin $\left(0.87 \mathrm{pmol} \cdot \mathrm{min}^{-1} \cdot \mathrm{kg}^{-1}\right)$ showed a significant intermediate effect $(p<0.05$ compared with the higher dose of insulin $\left(1.4 \mathrm{pmol} \cdot \mathrm{min}^{-1} \cdot \mathrm{kg}^{-1}, p<0.1\right)$ compared with control; data not shown). Infusion of B1-B'29 D also prolonged the hypoglycaemic effect of a smaller insulin bolus $(173 \mathrm{pmol} / \mathrm{kg}, p<0.001)$, during which the plasma glucose levels fell from $4.5-5.0$ to $2.7-3.5 \mathrm{mmol} / 1$ (data not shown).

The effects of the insulin or dimer infusions on either metabolic clearance rate or apparent distribution space of the insulin bolus $(700 \mathrm{pmol} / \mathrm{kg})$ were compared after subtraction of background-infusion immunoreactive analogue levels. The apparent distribution space of the insulin bolus $(106.4 \pm 11.9 \mathrm{ml} / \mathrm{kg})$ was sig-

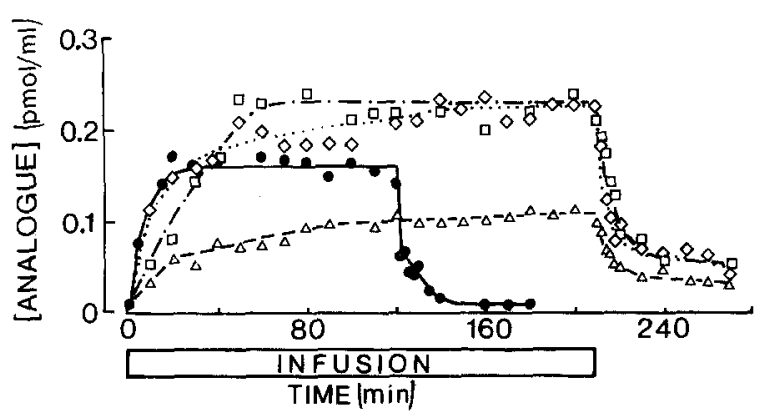

Fig. 2. Plasma distribution kinetics from a representative low-dose infusion of insulin $(-\rightarrow)$, B1-B'29 D $(\Delta-\Delta), B 1-B^{\prime} 1 \quad D$ $(\square-\square)$, or B29-B'29 D $(\diamond \cdots \cdots \diamond)$. Insulin was infused for $2 \mathrm{~h}$ at $2.7 \mathrm{pmol} \cdot \mathrm{min}^{-1} \cdot \mathrm{kg}^{-1}$ and the dimers for $3.5 \mathrm{~h}$ at $1.0-1.5 \mathrm{pmol}$. $\min ^{-1} \cdot \mathrm{kg}^{-1}$

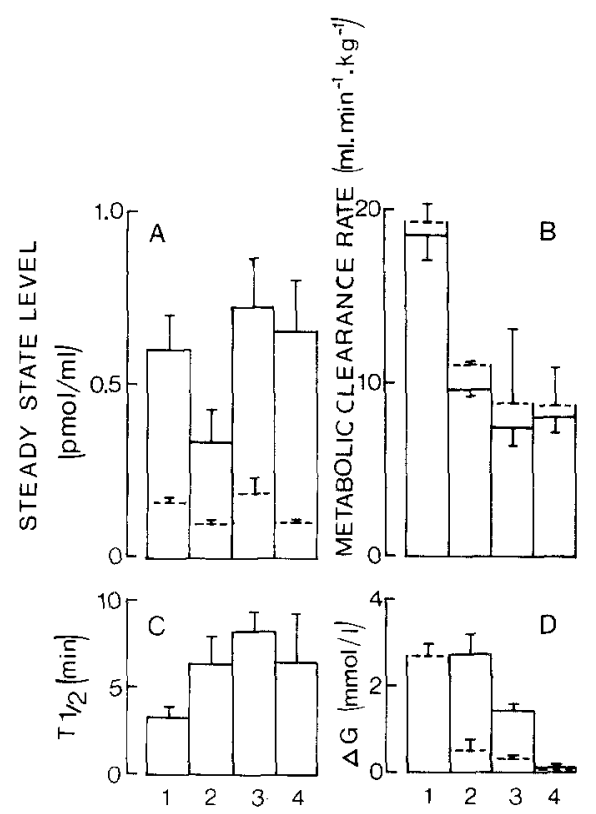

Fig.3A-D. Results of single constant infusions of insulin (1), B1-B'29 D (2), B1-B'1 D (3) or B29-B'29 D (4). Data from two or three experiments with each at either low (broken lines) or high (solid lines) dose are means and range for $\mathbf{A}$ serum steady-state analogue concentration, $\mathbf{B}$ metabolic clearance rates, $\mathbf{C}$ initial half disappearance time $\left(t_{1 / 2}\right.$, the mean values from both low and high doses are shown) and $\mathbf{D}$ fall in plasma glucose during $120 \mathrm{~min}$ infusion $(\Delta \mathrm{G})$. No effect on glucose levels was measured during the high-dose insulin infusions because a glucose clamp was used to prevent dangerous hypoglycaemia

nificantly reduced by the dimer $(44.5 \pm 8.4 \mathrm{ml} / \mathrm{kg}$, $p<0.02$ ), but not by the equipotent insulin infusion $(102.7 \pm 8.2 \mathrm{ml} / \mathrm{kg})$. The metabolic clearance rate of the insulin bolus $\left(14.7 \pm 0.5 \mathrm{ml} \cdot \mathrm{min}^{-1} \cdot \mathrm{kg}^{-1}\right)$ was also reduced by the dimer $\left(10.7 \pm 2.8 \mathrm{ml} \cdot \mathrm{min}^{-1} \cdot \mathrm{kg}^{-1}, p<0.1\right.$ compared with control, $p<0.05$ compared with insulin infusion), but not by the insulin infusion (16.4士 $0.7 \mathrm{ml} \cdot \mathrm{min}^{-1} \cdot \mathrm{kg}^{-1}$ ).

The plasma steady-state levels of the equipotent doses of insulin and B1-B'29 D showed that eight to nine times more dimer than insulin was required for the same biological response (Fig.1), i.e., B1-B'29 D had a 

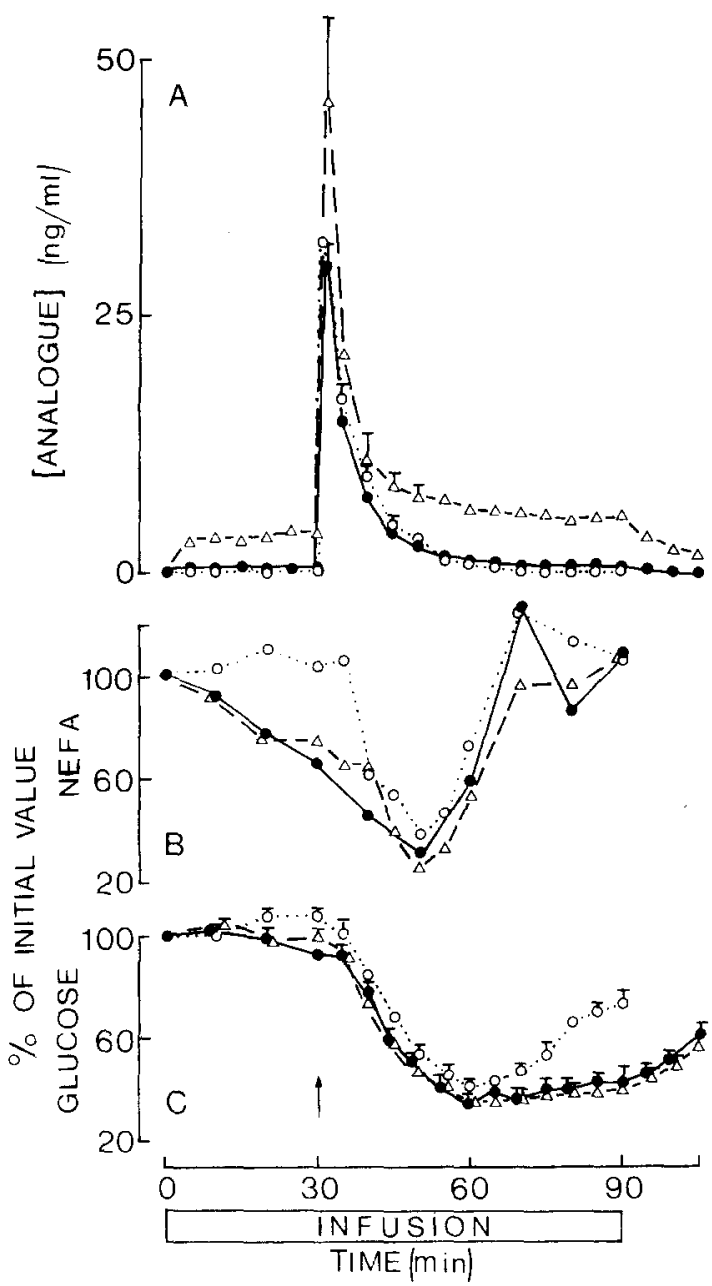

Fig. 4A-C. Interaction experiments with infusion of either saline $(\mathrm{O} \cdots \mathrm{O})$ or equipotent doses of insulin $(-$ ) or B1-B'29 D $(\triangle-\Delta)$ in the presence of a bolus of insulin $(700 \mathrm{pmol} / \mathrm{kg})$ given $30 \mathrm{~min}$ (indicated by the arrow) into the infusion. Data from four experiments for each substance (two for NEFA) are means \pm SEM (when variance is larger than symbol) for $\mathbf{A}$ immunoreactive analogue concentrations, $\mathbf{B}$ plasma NEFA, and $\mathbf{C}$ plasma glucose. Analogue concentrations in $\mathbf{A}$ are in mass rather than molar units since the samples from the B1-B'29 D infusions contained a mixture of insulin and dimer

biopotency of $11.2 \%$ on a molar basis. Using this potency and the data from the 3.5 -h infusion of the three dimers, the biopotencies of the other two dimers were estimated at 3\%-3.5\% for B1-B'1 D and $0.3 \%-1.7 \%$ for B29-B'29D. These values were markedly lower than their lipogenic potencies in isolated adipocytes in vitro $(80 \%, 30 \%$ and $13 \%$ for B1-B'29 D, B1-B'1 D and B29-B'29 D, respectively).

\section{Discussion}

The rates of metabolism of chemically-modified monomeric insulins have been reported to be directly proportional to their biological responses in vivo and to their binding potencies in vitro in isolated rat liver plasma

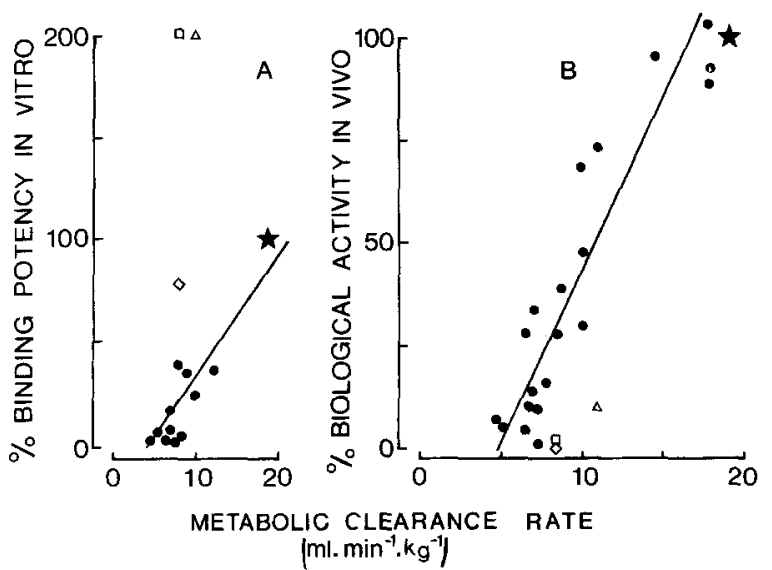

Fig.5. Relationship between metabolic clearance rate at a steadystate level of $0.5 \mathrm{pmol} \cdot \mathrm{ml}^{-1}$ and A percentage binding potencies in isolated liver plasma membranes or adipocytes, or $\mathbf{B}$ percentage biological activities in vivo (potencies are on a molar basis). Data for insulin ( $\star$ ) and several chemically-modified monomeric insulins and proinsulin (O) are from [4], with the linear regression of their data shown by the line (for $\mathrm{A}, \mathrm{r}=0.932, p<0.001$; for $\mathrm{B}, r=0.912, p<0.001$ ). The results for B1-B'29 D, B1-B'1 D, and B29-B'29 D are shown by $\Delta$, $\square$, and $\diamond$, respectively

membranes or adipocytes $[1,4]$. Figure 5 illustrates these two relationships and demonstrates that covalentlylinked insulin dimers showed marked deviations from the correlations. The most striking observation is the dissociation of degradation in vivo (i.e. metabolic clearance rates) from receptor binding affinities in vitro (Fig. 5A). Impairment in the distribution of the dimers to the site of cell surface receptors is one possible explanation, since distribution is primarily by diffusion and therefore dependent upon molecular size. Although their plasma distribution kinetics were slower than those of insulin (Fig.2), the measured distribution spaces of insulin and the dimers were similar and must therefore be regarded as evidence against impaired distribution.

It is perhaps more likely that the dimers, even when receptor bound, are less rapidly degraded than previously studied monomeric analogues. This explanation would support the idea that the processes of internalisation and subsequent degradation are linked to biological action. The post-binding events which initiate the process of internalisation and subsequent degradation are not understood, but it is of interest that receptorbound dimers also show reduced ability to initiate effects on lipogenesis and lipolysis in isolated adipocytes. This property would be expected to result in partial antagonism of insulin by the dimers.

It is interesting to note that the plasma immunoreactive analogue concentrations of the dimers, unlike insulin, failed to return to baseline levels $60 \mathrm{~min}$ after termination of the infusion (Fig, 2). With chemically-modified monomeric insulins an inverse correlation has been found between the plasma concentrations at $60 \mathrm{~min}$ after termination of the infusion and the rates of degrada- 
tion of the materials in vivo (unpublished observations). A likely explanation is recycling of immunoreactive material back into the plasma pool.

All three of the dimers had lower hypoglycaemic effects than expected from their rates of metabolism (Fig.5B), again suggesting partial competitive antagonism.

Partial antagonism of insulin degradation in vivo was demonstrated by the interaction experiments in which the apparent distribution space and metabolic clearance rate of insulin were reduced by B1-B'29 D but not by an equipotent dose of insulin. This is the expected result if the dimer, acting as an antagonist with a high binding affinity, reduces the number of available receptor sites without producing a commensurate biological effect. These observations are consistent with those of others who have reported reductions in the apparent distribution space and metabolic clearance rate of a bolus of iodoinsulin tracer by a high-dose infusion of insulin [12].

Plasma NEFA were found to be more sensitive than glucose to the effects of a low dose of insulin as previously reported $[13,14]$. Insulin has been shown to control NEFA concentration primarily by modulating output from peripheral stores [14]. On the other hand, the hepatic effect of insulin on glucose production is the predominant determinant of peripheral glucose concentration at low insulin concentrations, with a further effect in increased peripheral uptake only at high physiological levels $[15,16]$. A bolus of insulin alone (173 or $700 \mathrm{pmol} / \mathrm{kg}$ ) caused an immediate rapid fall in plasma NEFA and glucose. As plasma insulin concentrations rapidly decreased, recovery of both NEFA and glucose would be aided by the stimulatory action of counter-regulatory hormones, such as glucagon, catecholamines and adrenaline on glucose production in the liver and lipolysis in adipose tissue $[17,18]$. A low-dose infusion of insulin (and an equipotent dose of B1-B'29 D) prolonged the hypoglycaemic effect of an insulin bolus but were unable to prevent the recovery of NEFA. This suggests that the stimulatory action of counter-regulatory hormones was stronger than the inhibitory action of insulin in peripheral tissue (i.e., on lipolysis) but not in the liver (i.e., on gluconeogenesis or glycogenolysis).

Covalently-linked insulin dimers had slower plasma distribution kinetics, reduced rates of metabolism and markedly diminished hypoglycaemic effects in vivo compared with insulin. The apparent partial competitive antagonism of insulin by dimers that has been observed in vitro was investigated in vivo and partial antagonism of insulin metabolism by one of the dimers was directly demonstrated.

Acknowledgements. The authors wish to thank Ms. Prestwich for her technical assistance during the experiments in vivo. We are grateful to The Wellcome Trust (London), The British Diabetic Association and St. Thomas' Hospital Research (Endowments) Committee for their financial support.

\section{References}

1. Jones RH, Dron DI, Ellis MJ, Sönksen PH, Brandenburg D (1976) Biological properties of chemically modified insulins. I. Biological activity of proinsulin and insulin modified at A1-glycine and B29-lysine. Diabetologia 12: 601-608

2. The Peking Insulin Structure Research Group (1974) Studies on the insulin crystal structure: the molecule at $1.8 \mathrm{~A}$ resolution. Sci Sin 17: 752-778

3. Pullen RA, Lindsay DG, Wood SP, Tickle IJ, Blundell TL, Wollmer A, Krail G, Brandenburg D, Zahn H, Gliemann J, Gammeltoft S (1976) Receptor-binding region of insulin. Nature 259: 369-373

4. Jones RH, Quine KH, Tatnell MA, Dron DI, Brandenburg D, Lindsay D (1977) Chemically modified insulins: the relationship between biological activity and metabolism. Diabetologia 13: 405 (Abstract)

5. Willey KP, Tatnell MA, Jones RH, Schüttler A, Brandenburg D (1980) Biological properties of covalent insulin dimers. In: Brandenburg D, Wollmer A (eds) Insulin chemistry, structure, and function of insulin and related hormones. deGruyter, Berlin New York, pp 425-431

6. Thomas SL, Wisher MH, Brandenburg D, Sönksen PH (1979) Insulin action on adipocytes. Biochem J 184: 355-360

7. Schüttler A, Brandenburg D (1982) Preparation and properties of covalently-linked insulin dimers. Hoppe-Seyler's Z Physiol Chem 363: $317-330$

8. Dole VP, Meinertz H (1960) Microdetermination of long-chain fatty acids in plasma and tissues. J Biol Chem 235: 2595-2599

9. Sönksen PH, Tompkins CVT, Srivastava MC, Nabarro JDN (1973) A comparative study on the metabolism of human insulin and porcine proinsulin in man. Clin Sci Mol Med 45: 633-654

10. Morgan CR, Lazarow A (1963) Immunoassay of insulin. Two antibody system plasma insulin levels of normal, subdiabetic and diabetic rats. Diabetes 12: 115-126

11. Tatnell MA, Jones RH (1981) Effects of $\mathrm{pH}$ and $\mathrm{NaCl}$ concentrations on binding of covalently-linked insulin dimers to liver plasma membranes. Hoppe-Seyler's Z Physiol Chem 362: 1315-1321

12. Wick AN, Drury DR (1958) Effects of superimposed native insulin on disposal of iodoinsulin in the body. Proc Soc Exp Biol Med 97: $514-416$

13. Schade DS, Eaton RP (1977) Dose response to insulin in man: differential effects on glucose and ketone body regulation. J Clin Endocrinol Metab 44: 1038-1053

14. Cheng JS, Kalant K (1970) Effects of insulin and growth hormone on the flux rates of plasma glucose and free fatty acids in man. J Clin Endocrinol 31: 647-653

15. Brown PM, Tompkins CV, Juul S, Sönksen PH (1978) Mechanism of the action insulin in diabetic patients: a dose related effect on glucose production and utilisation. Br Med J I: 1239-1242

16. Tompkins CV, Brandenburg D, Jones RH, Sönksen PH (1981) Mechanism of action of insulin and insulin analogues. Diabetologia 20: 94-101

17. Cherrington AD, Vranic M (1974) Effect of interaction between insulin and glucagon on glucose turnover and FFA concentration in normal and depancreatised dogs. Metabolism 23: 729-744

18. Cryer PE (1981) Glucose counterregulation in man. Diabetes 30 : 261-266

Received: 24 August 1983

and in revised form: 4 May 1984

Dr. Richard H.Jones

Department of Medicine

St. Thomas' Hospital Medical School

London SE1 7EH

UK 